\title{
Writing in the Margins: Mainstream News Media Representations of Transgenderism*
}

\author{
Thomas J Billard \\ Annenberg School for Communication \& Journalism, \\ University of Southern California \\ tbillard@usc.edu
}

August 29, 2016

\begin{abstract}
This study examines representations of transgender individuals and identity in mainstream American newspapers in an effort to understand the extent to which the transgender community is legitimized or delegitimized by news media. To do so, 200 articles from 13 of the 25 most circulated daily newspapers in the United States were coded for the presence or absence of Legitimacy Indicators. The study finds that mainstream newspaper coverage of the transgender community is extremely limited. What coverage existed, however, contains a significant amount of delegitimizing language, which it is argued will detrimentally impact both the projected legitimacy of transgender claims in the political arena and public perceptions of the transgender community.
\end{abstract}

Keywords transgender, journalism, newspapers, legitimacy, content analysis

Cite as Billard, Thomas J. 2016. "Writing in the Margins: Mainstream News Media Representations of Transgenderism." International Journal of Communication 10: 4193-4218.

\footnotetext{
${ }^{*}$ The research presented in this article was originally conducted while the author was at the George Washington University. An earlier version of this article was presented at the annual meeting of the International Communication Association, May 2015 in San Juan, Puerto Rico. The author would like to thank Kimberly Gross for her guidance in the early phases of this project, as well as Patti Riley for her comments on an earlier draft of this article. The author would also like to thank the anonymous reviewers, whose thorough critiques greatly improved the article.
} 


\section{Introduction}

With the rise of a generation better versed in the issues facing lesbian, gay, bisexual, and transgender (LGBT) Americans and an increase in LGBT visibility in entertainment media, many academics have dedicated themselves to understanding this minority community more empirically. Yet, the wealth of academic research that is available on media representations of the LGBT community focuses largely on the L and G portions of the acronym. Even within the already-marginalized LGBT community, transgender individuals are further marginalized, not only in daily life, but also in rights advocacy and academic research. Consequently, queer scholars have recently increased the attention dedicated to media representations of transgender individuals (Chavez \& Griffin, 2012; Spencer, 2015), primarily through qualitative and critical-cultural studies (Capuzza, 2015).

Transphobia permeates American culture, a culture that simultaneously informs and is informed by media. There is a consequent vicious cycle of ignorance and hatred toward transgender individuals that is reflected in mainstream media representations of, societal attitudes toward, and public policy regarding transgenderism. ${ }^{1}$ The extant literature shows that news media consistently misname and misgender transgender individuals (e.g., Barker-Plummer, 2013; Squires \& Brouwer, 2002), misrepresent transgender identity (e.g., MacKenzie \& Marcel, 2009; Schilt \& Westbrook, 2009), portray transgender individuals as "tricksters" who live out their gender to seduce heterosexuals (e.g., Sloop, 2000; Squires \& Brouwer, 2002), and sexualize the transgender body (e.g., MacKenzie \& Marcel, 2009; Sloop, 2000). However, only two studies so far have provided larger-scale empirical analyses of news media content: Capuzza (2014) analyzed journalists' sourcing practices primarily in the coverage of Caster Semenya and Chelsea Manning, and Schilt and Westbrook (2009) provided some frame analysis of articles about transgender murder victims. Therefore, a larger-scale empirical analysis of news media content over time, and across both several news sources and story types, is required to answer some of the questions left unanswered by past studies.

Moreover, the transgender community requires legitimacy in order to further its claims in the political arena. The present study investigates whether mainstream news media discuss transgenderism in a legitimizing or delegitimizing manner, which will significantly impact both policy and public perception. Further, there are concerns that mainstream news media produces so little coverage of transgender issues and individuals that their absence further serves to delegitimize transgender political claims. To provide evidence for these arguments, the study examines legitimacy in mainstream newspapers in the United States using a novel set of "Legitimacy Indicators," which represent many elements constitutive of self-identifications and human dignity for transgender individuals. Using these Indicators, a content analysis was conducted of mainstream American newspaper articles that discuss transgender issues and/or individuals.

\subsection{The Legitimizing Function of News Coverage}

As a marginalized population, transgender citizens require systematic political protection and a fundamental change to current political structures to ensure their rights, as well as a change in overall American culture that accepts them as equals deserving of respect and proper treatment. While entertainment media contribute immensely to the formation of cultural attitudes and can greatly contribute to acceptance of the LGBT community (e.g., Calzo \& Ward, 2009; Riggle, Ellis,

\footnotetext{
${ }^{1}$ Although the GLAAD media reference guide lists "transgenderism" under "terms to avoid" out of concern that it pathologizes transgender identity, without the term "transgenderism" there exists no means to express the complex and intersecting concepts of transgender identity, embodiment, personhood, experience, etc. "Transgenderism" is an all-encompassing term that does the work of several terms at once, and is used as such throughout the pertinent literature, including most of the work cited in this manuscript and in the title of one of the leading journals in the study of gender identity and transgender issues, the International Journal of Transgenderism. Thus, I have employed the term in this manuscript for the academic and conceptual work it performs.
} 
\& Crawford, 1996; Schiappa, Gregg, \& Hewes, 2006), the news media has primary influence in the political realm and serves as the primary agent of legitimization for communities and their issues.

A solid body of literature has demonstrated the significance of news coverage to the perceived legitimacy and political viability of different groups and issues. Hallin (1986) first proposed a model of three spheres of news media coverage that dictate the projected legitimacy of an issue or a group of people (see Figure 1). These spheres occupy concentric spaces with the "Sphere of Consensus" at the center, enclosed within the "Sphere of Legitimate Controversy," which itself is enclosed within the "Sphere of Deviance." Each sphere is governed by different reporting norms, with the Sphere of Legitimate Controversy as the sole "province of objectivity" (Hallin, 1986, p. 116). Within the Spheres of Deviance and Consensus, journalists are not expected to be objective; rather, they are expected to either disregard or denounce the deviant and advocate the consensus. In between, in the Sphere of Legitimate Controversy, legitimized parties are permitted to discuss legitimized issues and be reported on disinterestedly (Hallin, 1986).

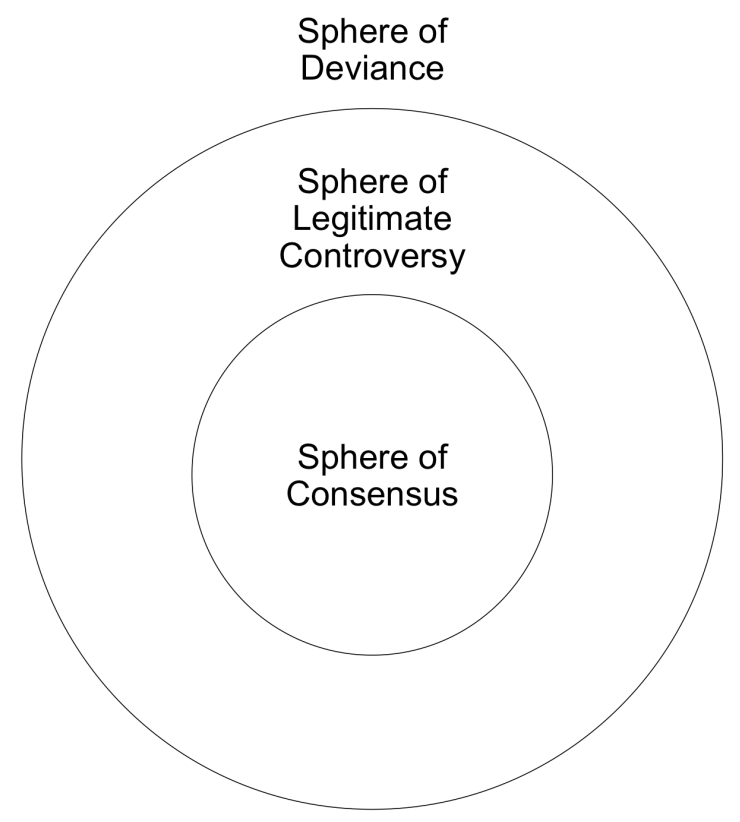

Figure 1: Spheres of consensus, controversy, and deviance. Adapted from Hallin (1986).

Hallin (1986) furthermore demonstrated how news coverage of the Vietnam War at various times regarded different parties as deviant (anti-war protestors) or legitimate (politicians, generals, troops), and how legitimacy was conferred through the use of particular framings and discourses. While Hallin looked at both television news and newspaper coverage (with particular attention paid to television), subsequent scholars have demonstrated the particular significance of newspaper coverage to the legitimacy of different political issues and protest groups (Luther \& Miller, 2005; Murray, Parry, Robinson, \& Goddard, 2008; Taylor, 2014). In their research on coverage of pro- and anti-Iraq War demonstrations, Luther and Miller (2005) found that newspaper coverage delegitimizes 
those groups that "challenge the status quo" (p. 81) through the use of "delegitimizing cue words" (p. 87), supporting the similar claims of previous research (Gitlin, 1980; McLeod \& Hertog, 1992). Furthermore, Taylor (2014) showed that the projected legitimacy of groups could decrease (and thus, conversely, increase) over time as the political climate evolves, and these changes in legitimacy can be observed through changes in "subtle lexical choices" (p. 48) journalists make in their articles. However, as Taylor (2014) points out, Hallin (1986) and subsequent studies using his model (Luther \& Miller, 2005; Murray, Parry, Robinson, \& Goddard, 2008) do not "outline the distinguishing features by which legitimacy and deviance are conferred" (p. 41). This is a shortcoming addressed with the Legitimacy Indicators proposed in this paper, which operationalized delegitimizing discourse on transgender issues and identity.

Of course, the other manner in which groups and issues are delegitimized is through invisibilitythrough news media's refusal to cover them (Hallin, 1986; see also Gross, 2001). In what Gerbner and Gross (1976) called "symbolic annihilation," those on the edges of political hierarchies and social acceptance are kept marginalized partly through being ignored (see also Gross, 1991). This "symbolic annihilation" for transgender people is ending (Arune, 2006; J. Gamson, 1998a; Roen, Blakar \& Nafstad, 2011), but the language used in this early news coverage may or may not be delegitimizing. As Yep, Russo, and Allen (2015) write, "[l]anguage constructs, affirms, and invalidates identities" (p. 74), and the language used in news media determines the perceived legitimacy of transgender claims in the political realm.

\subsection{Transgenderism in the News}

Although a wealth of research on media representations of the LGBT community exists, the majority of that research focuses on the $\mathrm{L}$ and $\mathrm{G}$ portions of the acronym, while the $\mathrm{T}$ portion is relatively ignored (Spencer, 2015). In recent years, research on media representations of transgenderism has increased (Chvez \& Griffin, 2012; Spencer, 2015). However, as Capuzza (2015) points out, the majority of this research has utilized critical-cultural approaches, rather than empirical social science approaches, as is often the case in scholarship on minority media representations (Dixon \& Williams, 2015).

The extant literature on news media representations of transgenderism in particular consists mostly of case studies of news coverage of public figures (Capuzza, 2015; Meyerowitz, 1998; Pieper, 2013; Skidmore, 2011) and hate-crime victims (Barker-Plummer, 2013; Chvez, 2010; MacKenzie \& Marcel, 2009; Sloop, 2000; Squires \& Brouwer, 2002; Willox, 2003). As noted by Spencer (2015) and Capuzza (2015), this literature demonstrates the ways in which news media coverage disciplines and stereotypes transgender identity (see also Barker-Plummer, 2013; Cloud, 2014; Sloop, 2004). In reviewing these findings, four clear patterns emerge, each of which contributes to the delegitimization of transgender individuals and issues: (1) misnaming and misgendering, (2) misrepresentations of transgender identity, (3) use of the transgender "trickster" trope, and (4) sexualization of the transgender body. ${ }^{2}$

First, past research has documented numerous incidences of misnaming and misgendering of transgender people in news media, which constrains transgender agency and delegitimizes transgender self-identifications (Barker-Plummer, 2013; Capuzza, 2015; Cloud, 2014; Hale, 1998; Schilt \&

\footnotetext{
${ }^{2}$ Capuzza (2015) identified a similar pattern and organized her literature review around four themes in news coverage: transgender people as "deceivers," medicalization of the transgender body, conflation of sex and gender, and "problematic language" (p. 95-96). The present study's categorizations are simultaneously more specific (sexualization and misnaming/misgendering) and broader (misrepresentations of transgender identity) to categorize the discourses identified in past research more precisely by the ways in which they are delegitimizing. For example, medicalization of the transgender body is broken down and subsumed into sexualization (regarding focus on surgical alterations of genitalia) and misrepresentations of transgender identity (regarding pathologization of transgender identities).
} 
Westbrook, 2009; Siebler, 2010; Sloop, 2000; Squires \& Brouwer, 2002; Willox, 2003). Much of this research focused on coverage of the murder of Brandon Teena, and noted how frequently he was called by his birth name and how frequently feminine pronouns were used in news media (Siebler, 2010; Squires \& Brouwer, 2002; Willox, 2003). Beyond this explicit misnaming and misgendering, however, news sources also delegitimized Brandon Teena's transgender identity through language such as "the person often called Brandon Teena" (Hale, 1998), which, while not explicitly misnaming him, suggests that his name is artificial. In another instance, early news coverage of the murder of Gwen Araujo referred to hir ${ }^{3}$ as "Edward" or "Eddie" and with masculine pronouns (BarkerPlummer, 2013). Even later, as news coverage shifted to be more sympathetic to hir, Gwen was frequently misgendered through the use of "she"; news media insisted on using feminine pronouns despite her preference for gender neutral ones (Barker-Plummer, 2013). Schilt and Westbrook (2009) showed that these case studies are not examples of isolated instances, but that misgendering is a frequent occurrence in news coverage of transgender murder victims.

Second, several studies have discussed the various ways in which news media misrepresent transgender identity, among them equating transgender womanhood with drag performance (Ryan, 2009) and transvestitism (Barker-Plummer, 2013; MacKenzie \& Marcel, 2009; Schilt \& Westbrook, 2009). Just as common is the deployment of "wrong body discourse," or the definition of transgender identity as having been "born in the wrong body" (Barker-Plummer, 2013), which restricts the various identities that fall under the term "transgender" to a singular conception of (primarily postoperative) transsexualism. Sloop (2000) discussed the even more insidiously pathologized definition of transgender identity as a reaction against one's birth gender due to trauma - in the case of Brandon Teena, a reaction against his sexual abuse as a child - advanced in news media. Furthermore, news media often misrepresent transgender women as "deceptive gay men" (Schilt \& Westbrook, 2009 , p. 456), simultaneously equating transgender women with homosexual men and advancing the transgender "trickster" trope. Many scholars have noted the prevalence of the transgender "trickster" trope, most commonly associated with transgender murder victims, which serves as a way to blame transgender women for their own deaths (Barker-Plummer, 2013; MacKenzie \& Marcel, 2009; Schilt \& Westbrook, 2009; Sloop, 2000; Squires \& Brouwer, 2002; Willox, 2003). Most commonly in news media this trope takes the form of comments about transgender people "pretending" to be their self-identified gender, though sometimes the claim of "deception" is made directly (Squires \& Brouwer, 2002). Sloop's (2000) analysis of the rhetoric of new coverage surrounding Brandon Teena's murder and the subsequent film about his life and death discussed how the idea of "deception in the heartland" makes Brandon Teena's gender identity a transgression against core American values and an attack on American identity, thus justifying his murder as retribution for his treason. Early coverage of the murder of Gwen Araujo similarly justified the actions of hir murderers by claiming that Gwen deceived them, tricking them into sexual encounters and thus attacking their heterosexuality, for which hir murder was punishment (Barker-Plummer, 2013). As Schilt and Westbrook (2009) wrote, news media most frequently frame anti-transgender violence "as a response to actual or perceived deception of the perpetrator by the transgender person" (p. 446), thereby disciplining transgender identity for its transgressions against "reality."

Finally, news media coverage of transgender issues and individuals frequently sexualizes the transgender body, primarily through focus on sexual organs as the source of gender identity (Cram, 2012; Landau, 2012; Meyerowitz, 1998; Ryan, 2009; Schilt \& Westbrook, 2009; Sloop, 2000; Squires \& Brouwer, 2002), as well as through the portrayal of transgender women in particular as hypersexual (MacKenzie \& Marcel, 2009). This sexualization continues a trend that began with coverage of

\footnotetext{
3 "Hir" is a gender-neutral pronoun, as Gwen, while presenting a feminine appearance and using a feminine name, did not identify hirself as a woman or female, but as genderqueer (see Barker-Plummer, 2013 for further discussion of Gwen's pronoun preferences).
} 
Christine Jorgensen in the 1950s, which focused on her sexual organs as proof of her "legitimate" transition to womanhood (Meyerowitz, 1998). News coverage of Brandon Teena, for example, focused obsessively on his anatomy - primarily that he did not have a penis - and placed a particular focus on his sexual relationships with women (Sloop, 2000), sifting through the details of his anatomy and sexual history to determine how to locate his gender. As argued by Adams (2015), discussing transgender individuals in relation to their genitalia and sexual habits both "insults the dignity of the transgender individual" and again reduces transgender identity to a singular conception of post-operative transsexualism (p. 179).

\subsection{Legitimacy Indicators for Transgenderism}

Drawing on the pertinent literature as well as the National Lesbian and Gay Journalist Association Stylebook and GLAAD media reference guide, a set of nine "Legitimacy Indicators" was constructed to operationalize the more abstract concept of legitimacy. Together, these Indicators account for many of the various aspects of respecting the self-identifications and human dignity of transgender individuals. $^{4}$

Legitimacy Indicator 1: Naming indicates whether an author or speaker refers to a transgender individual by their name given at birth (delegitimizing) rather than their preferred, chosen name (legitimizing).

Indicator 2: Pronoun usage indicates whether an author or speaker refers to a transgender individual by their pronouns assigned at birth (delegitimizing) or their preferred pronouns (legitimizing).

Indicator 3: Past tense references indicates whether an author or speaker properly refers to a transgender individual's past by explicitly stating the person was a different gender than the one with which the individual currently identifies (delegitimizing) or by simply saying they were their self-identified gender (legitimizing).

Indicator 4: Application of terms indicates whether an author or speaker properly applies the terms "transgender," "transsexual," etc. (legitimizing), or does so improperly (delegitimizing).

Indicator 5: Characterizations of transgenderism indicates whether an author or speaker mischaracterizes transgenderism (delegitimizing) in one of many ways that include but are not limited to: categorizing transgender men with women or transgender women with men; equating transgenderism with drag, cross-dressing or transvestitism; and referring to transgenderism as a choice, lifestyle, disease, etc.

Indicator 6: Slurs and name-calling indicates whether an author or speaker refers to a transgender individual as a "tranny," "she-male," or other transphobic slur; that they equate transgenderism with sexual perversion, addiction, etc.; or that they call a transgender person by some name meant to offend, such as $\mathrm{s}(\mathrm{he})$, Mr. Mom, etc. (delegitimizing).

Indicator 7: Defamation indicates whether an author or speaker suggests a transgender individual has a criminal or amoral background without source or evidence, or where entirely irrelevant to the story (delegitimizing).

Indicator 8: Shock tactics indicates whether an author or speaker uses a transgender individual's gender identity as a shock tactic or hook to get a reader's attention (delegitimizing). Not all headline references to a transgender individual's gender identity are delegitimizing, only references in which the author attempts to surprise the audience by describing a person but then disclosing their gender identity as though it were unexpected.

Indicator 9: Genital focus/sexualization indicates whether an author or speaker focuses the discussion of a transgender individual on their genitalia or depicts the person as a sexual object (delegitimizing).

\footnotetext{
${ }^{4}$ Full Legitimacy Indicator descriptions provided to coders are available from the author.
} 
Because it is difficult to make normative assumptions about the "amount" of legitimacy or delegitimacy conferred on the topic of transgenderism by the news media, no hypotheses are proposed. To investigate the (de)legitimization of transgender issues and identities in U.S. newspapers, three research questions are investigated:

RQ1: To what extent are news media representations of transgenderism legitimizing versus delegitimizing?

$R Q 2:$ What is the nature of the delegitimizing representations?

$R Q 3:$ Is the amount of legitimizing representations increasing over time?

\section{Method}

To answer these questions, a content analysis of print news articles was conducted following Krippendorff's (2004) guidelines. To form an accurate picture of transgender representations across the entire country, a list of newspapers was selected from throughout the country for the sample. Furthermore, the sample was restricted to widely consumed, mainstream newspapers (rather than LGBT-specific/friendly ones) because their representations of transgenderism are disseminated to the general public, where the potential to influence large numbers of the population through projected legitimacy is the greatest. As Schilt and Westbrook (2009) write, "mainstream news media both reflect and shape dominant belief systems" (p. 445; see also W. A. Gamson, Croteau, Hoynes, \& Sasson, 1992).

The newspaper sample construction began with a list of the 25 most-circulated daily newspapers collected from the Alliance for Audited Media's September 2012 report. Half of the newspapers were sampled (rounded up to 13): the Wall Street Journal, USA Today, New York Times, New York Daily News, New York Post, Washington Post, Denver Post, Tampa Bay Times (previously St. Petersburg Times), Minneapolis Star Tribune, Philadelphia Inquirer, Orange County Register, Las Vegas Review-Journal, and Boston Globe. The sample was constructed from the Dow Jones's international news database Factiva using the search terms "transgender," "transsexual," "transgendered," "born a man," "born a woman," "born male," "born female," "tranny," and "she-male." The search was restricted to headlines and ledes (leads) to find stories in which transgender people or issues were the main focus, rather than find stories in which some other topic was the main focus but transgender individuals/issues were briefly mentioned. The search spanned ten years from January 1, 2004 to December 31, 2013. This allowed the coverage to be analyzed and determine: 1) whether legitimacy has increased over time, 2) how much coverage exists, and 3) the nature of that coverage.

The Factiva search with all of these parameters yielded 1642 articles. Articles were then deduplicated and those that did not contain one of the search terms in the headline or within the first five paragraphs of the article outside of the phrase "lesbian, gay, bisexual, and transgender" or one of its variants were removed. From that remaining pool of only 294 articles $(17.91 \%$ of the initial yield), $200(68.03 \%)$ were sampled randomly for coding. Articles were coded into one of six story type categories: art reviews, crime/murder, education, entertainment/celebrity, health, human interest, opinion/editorial, political, tabloid, ${ }^{5}$ or "other." The unit of analysis for this study was the paragraph, so each paragraph was coded for the presence or absence of each Legitimacy Indicator, as well as whether or not the paragraph contained discussion of a transgender woman, transgender man, non-binary/genderqueer transgender person, or no transgender person. Only articles' text content was coded; any images were not coded. Coding was conducted by the author

\footnotetext{
5 "Tabloid" stories were defined as any story that did not fit into one of the other coding categories and was also sensational or lurid in style. If the story did not fit into one of the other coding categories and was not sensation or lurid, it was coded as "other."
} 
and an undergraduate research assistant. Intercoder reliability was determined by selecting a $20 \%$ sub-sample for comparison between both coders. ${ }^{6}$ High intercoder reliability — at or above .90 - was achieved across all categories. Full intercoder reliability data can be found in the Appendix.

\section{Results}

From the sample of 200 articles, there were 2942 paragraphs to be coded, most of which came from the New York Times (21.1\% of all paragraphs), Boston Globe (13.3\%), Washington Post $(11.1 \%)$, New York Post (10.5\%), and Tampa Bay Times (10.1\%). The Wall Street Journal accounts for only $0.40 \%$ of paragraphs, all of which came from one article. Generally speaking, there was an increasing amount of coverage dedicated to stories pertaining to transgenderism over the 10 year span analyzed, although certain date ranges saw spikes punctuated around different events, such as the proposal of new legislation or a murder or, most noticeably in the data, the 2005 release of the film Transamerica (see Figure 2). However, a nonparametric Mann-Kendall test (Kendall, 1975; Mann, 1945) was conducted to determine if the apparent trend is monotonic. The results of the test were nonsignificant, $\tau=.242, p=.144$.

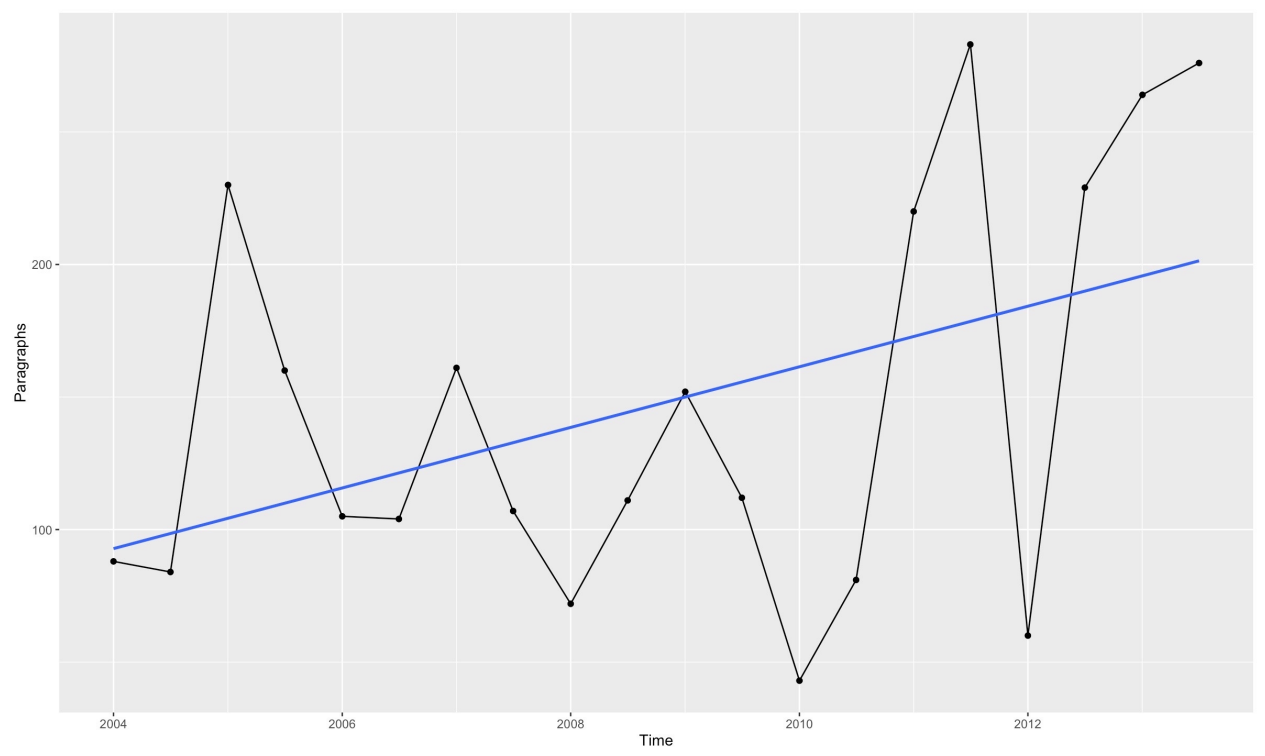

Figure 2: Coverage of transgenderism over time across all newspapers.

The only newspapers in the sample for which the increase in coverage was statistically significant were the New York Times $(\tau=.483, p=.004$; see Figure 3$)$ and Boston Globe $(\tau=.550, p=.001$; see Figure 4). All of the other news sources' coverage appeared to be periodic, clustered around certain events. Quite clearly in the data, for example, the Tampa Bay Times spiked in its coverage surrounding the firing of Susan Stanton from the position of Largo city manager, and each spike in their coverage subsequent to the initial incident followed a public statement by Ms. Stanton.

\footnotetext{
${ }^{6}$ Violations of Respect Indicators 7, 8, and 9 (defamation, shock tactics, and genital focus/sexualization, respectively) were quite rare. Therefore, in order to have useful intercoder reliability (ICR) data, the ICR sample was constructed of every article in which one of these Indicators was coded, plus a set of randomly selected articles to bring the final sample size up to $20 \%$ of all coded data.
} 


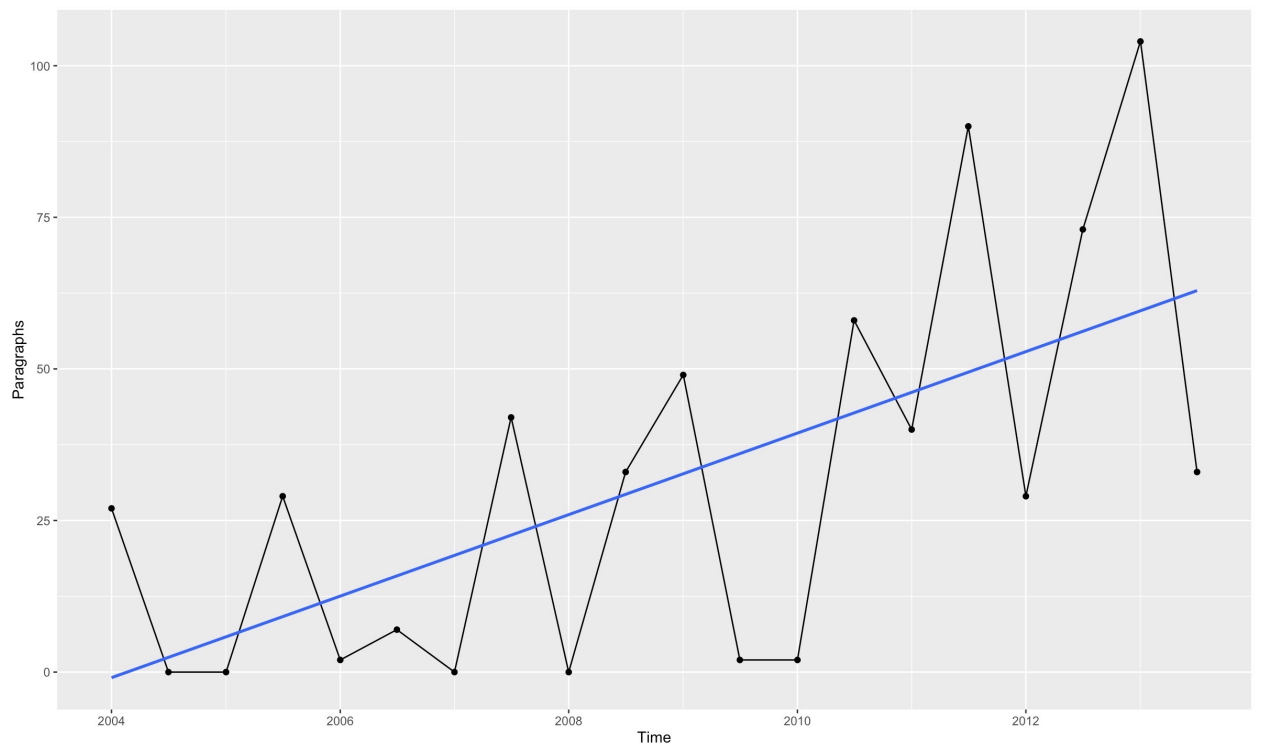

Figure 3: Coverage of transgenderism over time in the New York Times.

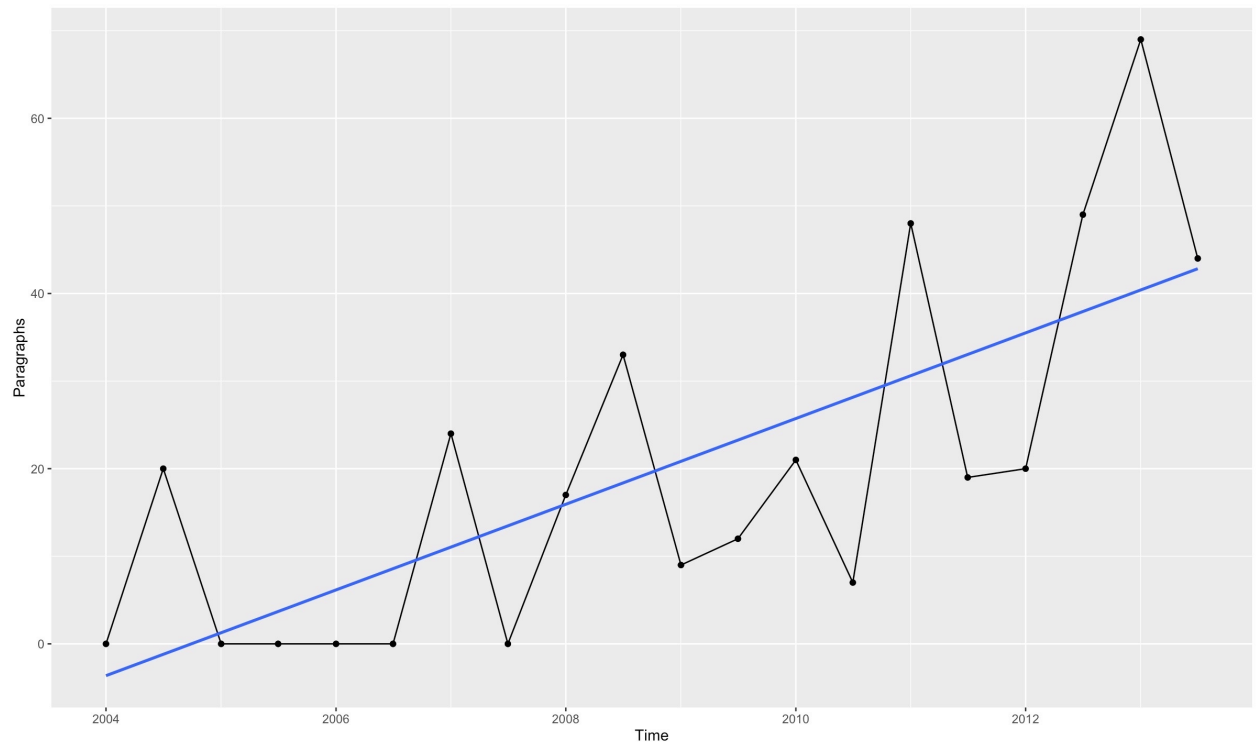

Figure 4: Coverage of transgenderism over time in the Boston Globe. 
The majority of transgender news coverage, as measured by percent of all paragraphs, was in political stories $(30.7 \%)$. Human-interest stories accounted for $15.4 \%$ of coverage, followed by crime/murder $(14.0 \%)$, tabloid $(8.63 \%),{ }^{7}$ opinion/editorial (8.09\%), entertainment/celebrity $(7.72 \%)$, art reviews (5.17\%), "other" (4.49\%), education $(3.33 \%)$, and health $(2.48 \%)$.

Over the 10-year span, between the 13 newspapers in the present study only 294 articles on transgenderism were published. The content analysis further showed that only $45.6 \%$ of all paragraphs coded discussed or mentioned a specific transgender person, and only $24.1 \%$ used - correctly or incorrectly - terms such as "transgender" and "transsexual." Of all paragraphs that mentioned or discussed a specific transgender person, $21.4 \%$ of coverage was dedicated to transgender men, compared to $77.5 \%$ to transgender women, and only $1.20 \%$ to non-binary/genderqueer transgender individuals.

Moving to the question of legitimacy, $14.2 \%$ of all paragraphs across all articles in the sampleincluding those paragraphs in which no transgender people are discussed/mentioned or transgender terms are used-contained delegitimizing language. Though by raw percentage the Wall Street Journal was the most delegitimizing newspaper in the sample with $54.6 \%$ of all their paragraphs containing delegitimizing language, the Wall Street Journal had only one article of 11 paragraphs in the sample. The New York Daily News and New York Post followed as the most delegitimizing newspapers with $25.4 \%$ and $21.4 \%$ of their coverage delegitimizing, respectively. Following them, the Minneapolis Star Tribune (21.0\% of all paragraphs), Tampa Bay Times (20.2\%), and Denver Post (18.1\%) were the most delegitimizing. Among the most legitimizing newspapers were the Las Vegas Review Journal (3.23\% of coverage delegitimizing) and Philadelphia Inquirer (6.61\%) (see Table 1).

Table 1: Delegitimacy by Source

\begin{tabular}{lc} 
Source $(\mathrm{n}=$ paragraphs $)$ & \% Coverage Delegitimizing \\
\hline Wall Street Journal $(\mathrm{n}=11)$ & 54.6 \\
New York Daily News $(\mathrm{n}=236)$ & 25.4 \\
New York Post $(\mathrm{n}=209)$ & 21.4 \\
Minneapolis Star Tribune $(\mathrm{n}=95)$ & 21.1 \\
Tampa Bay Times $(\mathrm{n}=297)$ & 20.2 \\
Denver Post $(\mathrm{n}=226)$ & 18.1 \\
Washington Post $(\mathrm{n}=328)$ & 14.3 \\
Boston Globe $(\mathrm{n}=392)$ & 12.0 \\
USA Today $(\mathrm{n}=53)$ & 9.43 \\
New York Times $(\mathrm{n}=620)$ & 7.58 \\
Philadelphia Inquirer $(\mathrm{n}=121)$ & 6.61 \\
Orange County Register $(\mathrm{n}=130)$ & 6.25 \\
Las Vegas Review Journal $(\mathrm{n}=124)$ & 3.23 \\
\hline
\end{tabular}

\subsection{Legitimacy Indicator 1: Naming}

Of all paragraphs that named a specific transgender person, $84.6 \%$ used the person's chosen name and only $15.4 \%$ referred to them by their name given at birth. Crime/murder stories and tabloid stories accounted for the most misnaming. All other story types referred to transgender people by their chosen names in over $80 \%$ of paragraphs. Crime/murder stories, however, referred to transgender people by their name given at birth $39.6 \%$ of the time, while tabloid stories did so $24.1 \%$ of the

\footnotetext{
${ }^{7}$ One hundred percent of tabloid stories came from the New York Daily News or New York Post.
} 
time (see Figure 5). In fact, crime/murder stories account for $35.0 \%$ of all misnaming. Misnaming was most frequent in the Minneapolis Star Tribune (66.7\% of all naming paragraph), followed by the Tampa Bay Times (38.5\%) and Washington Post (31.6\%). The only newspapers in the sample to contain no misnaming were the Philadelphia Inquirer, Orange County Register, and Las Vegas Review Journal. The Wall Street Journal contained no naming paragraphs in the one article in the sample. The results of a Mann-Kendall test assessing the trend of misnaming over time were nonsignificant, $\tau=-.273, p=.114$.

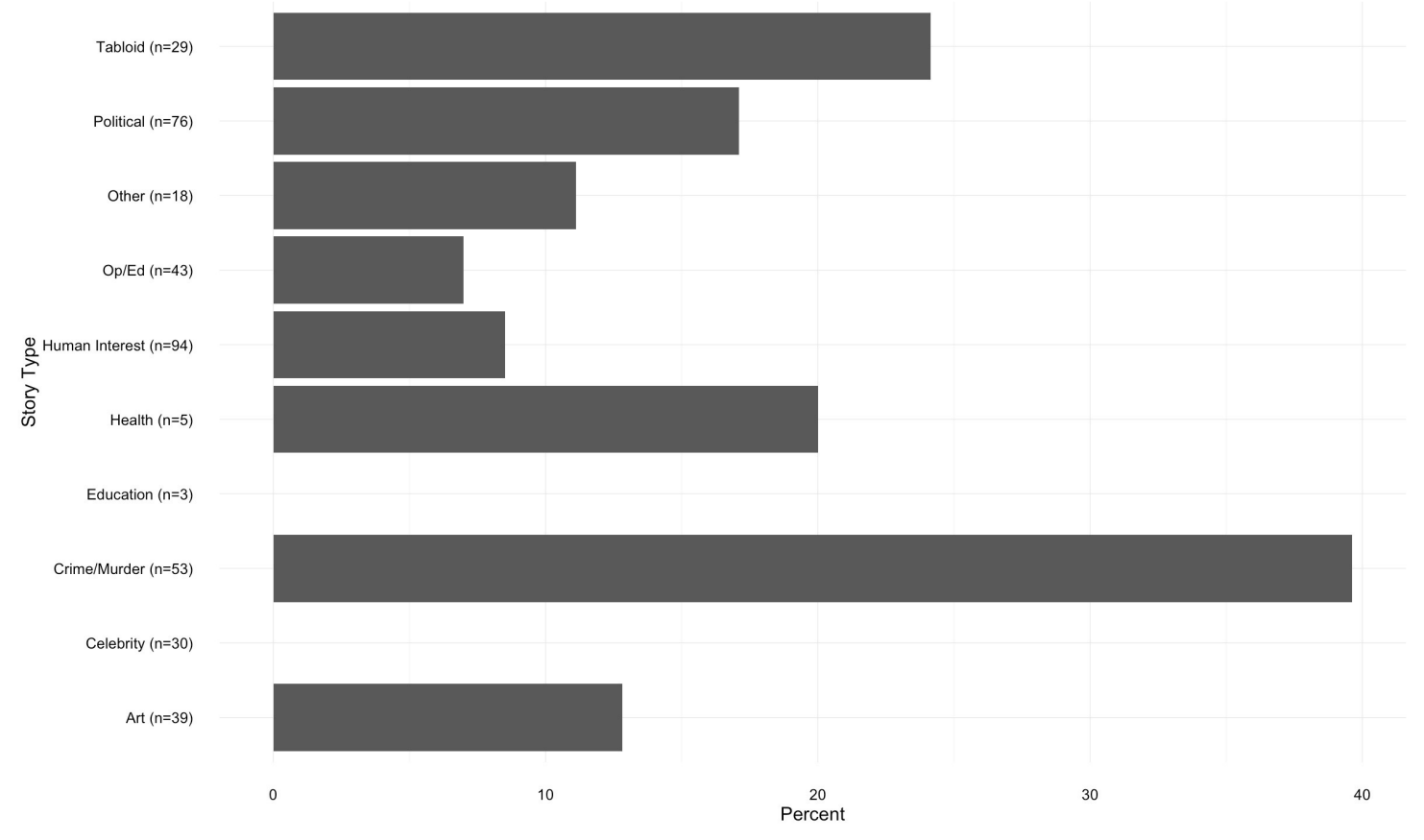

Figure 5: Percent of naming paragraphs using birth name by story type.

\subsection{Legitimacy Indicator 2: Pronoun Usage}

Much as with naming, $84.3 \%$ of paragraphs that used pronouns for a specific transgender person used their preferred pronouns and only $15.7 \%$ used their pronouns assigned at birth. Pronoun usage was most delegitimizing in opinion/editorial (36.7\% of pronoun-using articles), political (29.4\%), and tabloid $(20.0 \%)$ articles. While pronoun usage was delegitimizing in less than $20.0 \%$ of pronoun-using paragraphs among all other newspapers in the sample, the Tampa Bay Times used pre-transition pronouns in $53.2 \%$ of paragraphs, USA Today in 50.0\%, and Denver Post in $45.1 \%$. Again, as with naming, the Wall Street Journal contained no pronoun-using paragraphs in the one article in the sample. However, unlike with naming, pronoun usage has become more consistently legitimizing. The results of a Mann-Kendall test demonstrate a statistically significant decrease in the percentage of paragraphs using improper pronouns over time, $\tau=-.361, p=.033$ (see Figure 6). 


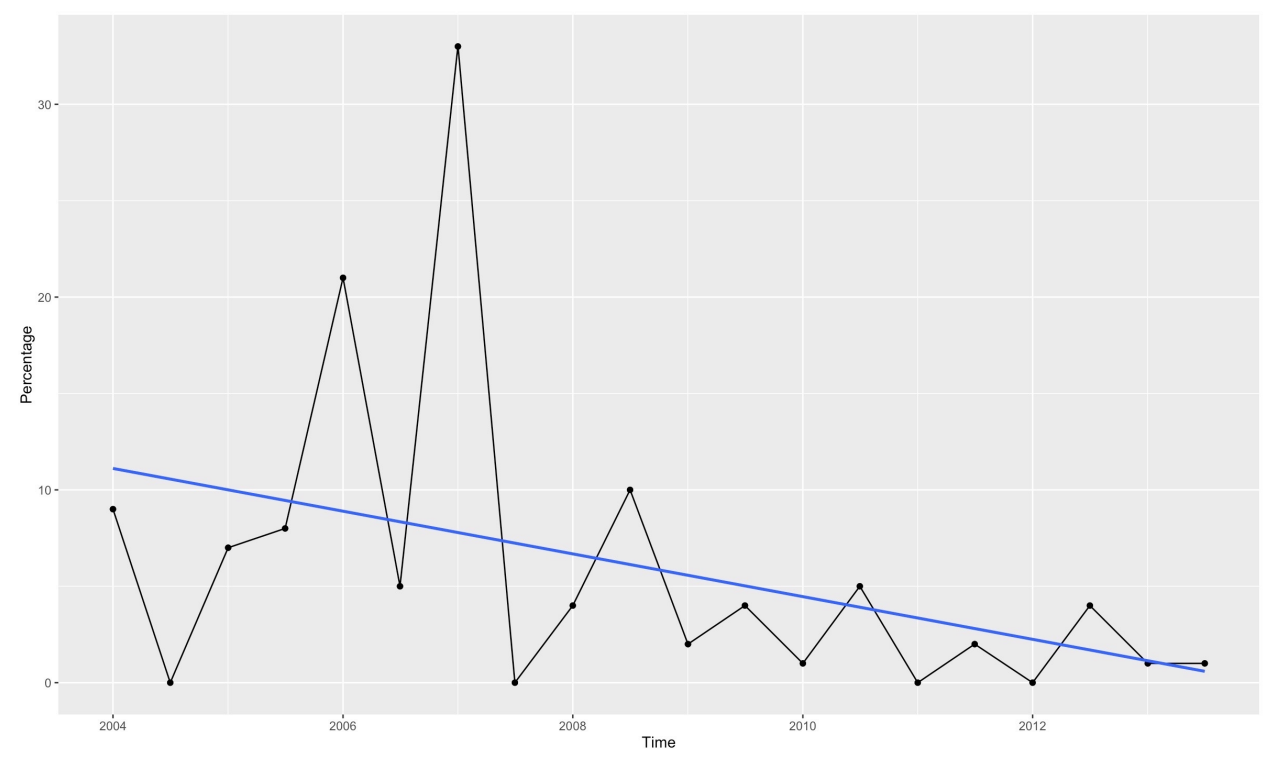

Figure 6: Percent of paragraphs using improper pronouns over time.

\subsection{Legitimacy Indicator 3: Past Tense References}

Of all paragraphs that referenced a specific transgender person's past, $37.4 \%$ did so in a delegitimizing manner, while $62.7 \%$ did so properly. Of all the story types of which there were more than 10 paragraphs containing past tense references, crime/murder stories contained the most delegitimizing references at $33.3 \%$ of paragraphs. Human-interest stories similarly referenced transgender people's pasts in a delegitimizing manner in $30.4 \%$ of all paragraphs containing past tense references. The results of a Mann-Kendall test assessing the trend of past tense references over time were nonsignificant, $\tau=.024, p=.919$.

\subsection{Legitimacy Indicator 4: Application of Terms}

Of all paragraphs containing transgender terms (which was $24.1 \%$ of all paragraphs coded), $16.2 \%$ applied improper terms (such as referring to a transgender person as "a transgender"), while 83.8\% used proper terms. The New York Daily News used delegitimizing terms in $40.9 \%$ of paragraphs containing transgender terms, followed by the Minneapolis Star Tribune (31.3\%), Denver Post (27.9\%), and Tampa Bay Times (27.3\%). The New York Times applied improper terms the least, with only $5.20 \%$ of term applications delegitimizing. By story type, human interest (23.5\%), political and health (both $16.7 \%$ ), and tabloid (14.5\%) stories were the most consistently delegitimizing. The increase in legitimizing applications of terms is clear, however. The results of a Mann-Kendall test demonstrate a statistically significant increase in the percentage of paragraphs applying proper terms over time, $\tau=.519, p=.002$ (see Figure 7 ).

\subsection{Legitimacy Indicator 5: Characterizations of Transgenderism}

Mischaracterizations of transgenderism were not extremely prominent with $3.30 \%$ of all paragraphs containing mischaracterizations. Of all paragraphs that discussed a specific transgender individual, 


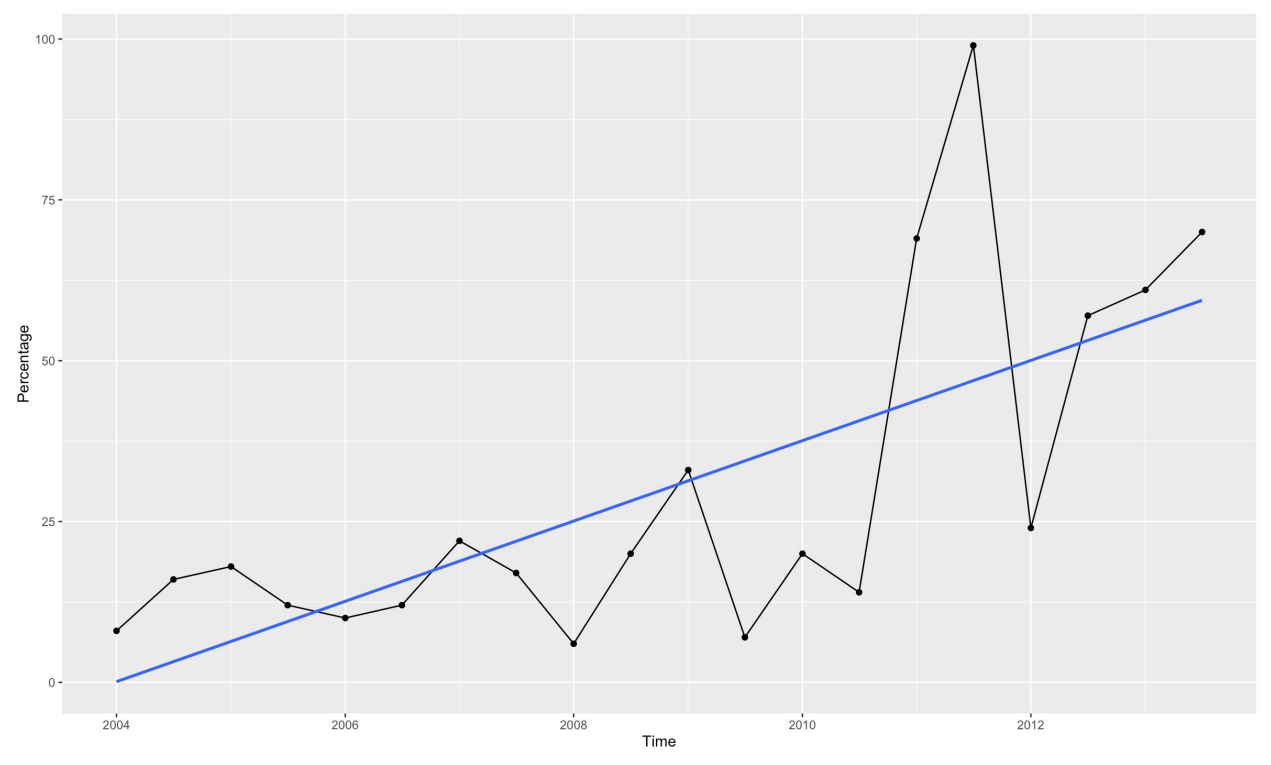

Figure 7: Percent of paragraphs applying terms legitimizingly over time.

however, $5.36 \%$ contained mischaracterizations. More specifically, transgender women were frequently mischaracterized. The percentage of paragraphs discussing a transgender woman in which transgenderism was mischaracterized is over 1.5 times higher than that for transgender men. Political stories accounted for the largest amount of mischaracterization of transgenderism at $28.1 \%$ of all paragraphs containing mischaracterizations, followed by crime/murder (26.0\%), entertainment/celebrity (12.5\%), and human-interest (11.5\%) stories. The results of a Mann-Kendall test assessing the trend of mischaracterizations of transgenderism over time were nonsignificant, $\tau=$ $-.077, p=.670$.

\subsection{Legitimacy Indicator 6: Slurs and Name-Calling}

Slurs and name-calling were found in $2.40 \%$ of all paragraphs and $3.57 \%$ of all paragraphs that discussed or mention a specific transgender person. In $62.9 \%$ of cases, slurs were directed against a transgender woman, while $5.71 \%$ were directed against a transgender man and $31.4 \%$ were directed against no specific transgender person (although they may still have been gendered slurs such as "tranny" and "she-male" which are anti-transgender women). The New York Daily News and the New York Post combined accounted for $58.6 \%$, and the Washington Post accounted for $12.9 \%$ of all slurs and name-calling in the sample. Only three news sources used no slurs at all: the Minneapolis Star Tribune, Philadelphia Inquirer, and Las Vegas Review Journal. While $31.4 \%$ of slurs and namecalling incidents were found in tabloid articles, celebrity news accounted for $18.6 \%$ and crime/murder stories accounted for $15.7 \%$. The results of a Mann-Kendall test assessing the trend of slurs and name-calling over time were nonsignificant, $\tau=-.277, p=.108$.

\subsection{Legitimacy Indicator 7: Defamation}

Defamation was found in $0.82 \%$ of all paragraphs that discussed a specific transgender person. Of the defamation found, however, $81.8 \%$ was directed specifically at transgender women, versus $9.09 \%$ 
each toward transgender men and no transgender person in particular. Opinion/editorial articles accounted for the most defamation (36.4\% of all paragraphs containing defamation), followed by tabloid, crime/murder, and political stories (18.2\% each). The results of a Mann-Kendall test assessing the trend of defamation over time were nonsignificant, $\tau=.146, p=.453$.

\subsection{Legitimacy Indicator 8: Shock Tactics}

Gender identity was used as a shock tactic to gain a reader's attention in $6.35 \%$ of all headlines and ledes. As with slurs and name-calling, $25.0 \%$ of headlines and ledes using shock tactics were found in tabloid articles, while celebrity news and crime/murder stories accounted for $18.8 \%$ each. The New York Times and New York Post each accounted for 25.0\% of headlines and ledes using shock tactics, followed by the New York Daily News (18.8\%). The results of a Mann-Kendall test assessing the trend of defamation over time were nonsignificant, $\tau=.019, p=.944$.

\subsection{Legitimacy Indicator 9: Genital Focus/Sexualization}

Genital focus/sexualization was found in only $1.40 \%$ of all paragraphs, though the percentage nearly doubles to $2.76 \%$ among paragraphs that discussed or mentioned a specific transgender person. Of all genital focus/sexualization, $90.0 \%$ was of a transgender woman, while $2.50 \%$ was of a transgender man and $7.50 \%$ was directed at no specific transgender person (no genital focus/sexualization was directed at non-binary transgender individuals; see Figure 8). Much like with slurs and namecalling, the New York Daily News and New York Post combined accounted for $57.5 \%$ of all genital focus/sexualization. Again, the Minneapolis Star Tribune, the Philadelphia Inquirer, and the Las Vegas Review Journal's coverage contained no instances of genital focus or sexualization, though in this case the Wall Street Journal and USA Today joined them. The New York Times, Washington Post, and Boston Globe each accounted for $10.0 \%$ of genital focus/sexualization, while the remaining newspapers accounted for less than $10.0 \%$ each. The results of a Mann-Kendall test assessing the trend of sexualization over time were nonsignificant, $\tau=-.081, p=.662$.

\section{Discussion}

The present study assessed to what extent news media representations of transgenderism are delegitimizing, using a novel set of Legitimacy Indicators, which operationalize legitimacy and account for the elements of respecting the self-identifications and human dignity of transgender individuals. Additionally, the study analyzed the nature of delegitimizing representations, identifying the most frequent types of delegitimizing language in news media content, and how this language use has evolved over time. This study fills a large gap in scholarship on transgender media representations as the first large-scale empirical analysis of news media content over time, and across both news sources and story types.

It is difficult to make any normative claims about the amount of delegitimizing language in news media coverage of transgenderism. Although this study provides concrete numbers for what percentage of paragraphs in stories about transgenderism contain delegitimizing language, there is no "right" amount of delegitimacy; one cannot identify a threshold of how much delegitimacy may "acceptably" be conferred on a group of people. However, it is clear from the present study that the criticisms of news media by transgender activists and scholars of transgender media representations are founded, though the amount of delegitimizing language in news media content is generally decreasing. 


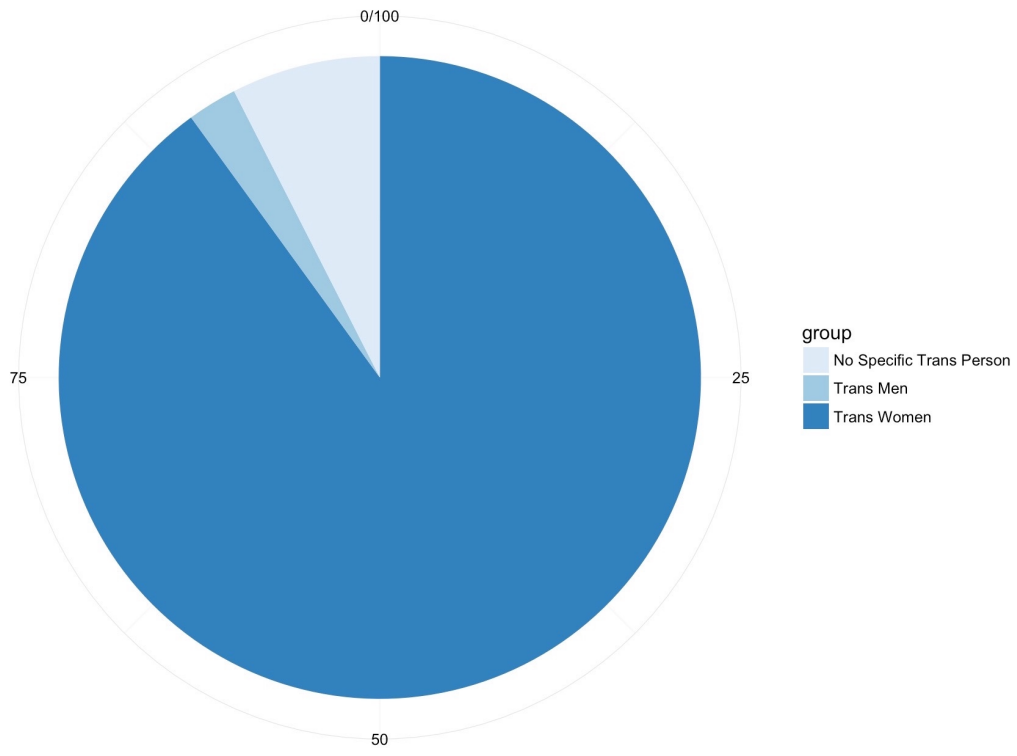

Figure 8: Percent of genital focus/sexualization by gender identity.

Most notably, there is very little coverage of transgenderism in mainstream news media. Over the span of ten years, among 13 of the United States' 25 most circulated daily newspapers, only 294 articles discuss transgender issues and individuals. This number is especially low considering that only $45.6 \%$ of all paragraphs coded mention a specific transgender person and only $24.13 \%$ use the terms "transgender," "transsexual," or some variant thereof, demonstrating that the majority of news coverage of transgender people and issues does not focus on them. This supplements the findings of Capuzza (2014), who argued that journalistic sourcing patterns lead to an underrepresentation of transgender voices in articles that discuss transgenderism and restrict transgender sources to providing "personal narratives" (p. 96) rather than allowing them to authoritatively speak on transgender issues.

Although there is a statistically significant decrease in the percentage of delegitimizing applications of terms over time, it is interesting to note that these changes lag significantly behind the 2006 changes in the Associated Press (AP) Style Guide's standards for reporting on the transgender community. Already in 2006 the AP issued clear guidance for properly reporting on transgenderism, but it was not until around 2010 that the amount of paragraphs containing delegitimizing applications of terms dropped below $20 \%$ and remained there. This supports the notion that a broader cultural evolution in transgender awareness increased the projected legitimacy of transgenderism, since the decreases in delegitimacy clearly were not tied to formal changes in reporting norms.

The two newspapers with the most delegitimizing coverage deserve special attention: the New York Daily News and New York Post, which might more appropriately be identified as tabloid papers (Pelizzon \& West, 2010), and which published all articles in the sample coded as tabloid stories. These two papers accounted for a large proportion of the measured delegitimization and, aside from the Wall Street Journal (which had only a total of 11 paragraphs in the sample), were the two most delegitimizing newspapers in the sample. They also contained the most slurs and sexualization. This 
level of delegitimacy is unsurprising however, considering the informal reporting of tabloid papers, with less emphasis on "objectivity" and a greater emphasis on scandal, often seen in the excessive use of "emphatic adjectives" (Baker, 2010, p. 317) and expos-type stories (Pelizzon \& West, 2010). J. Gamson (1998b), writing about tabloid talk shows, noted how tabloid coverage of transgender individuals sensationalizes ordinary aspects of life as a means of manufacturing interest, often at the expense of transgender self-identifications, in ways more explicit than traditional media would. Furthermore, tabloid coverage focuses on transgender anatomy, the "ambiguity" of which sells the programs and "reestablish[es] the logic of two distinct sexes" (J. Gamson, 1998b, p. 163), which the present study found in tabloid newspapers as well.

Interestingly, crime and murder stories comprised only $14.0 \%$ of all paragraphs in the sample, although they are the focus of most scholarship on transgender news media representations (e.g., Barker-Plummer, 2013; MacKenzie \& Marcel, 2009; Schilt \& Westbrook, 2009; Sloop, 2000; Squires \& Brouwer, 2002; Willox, 2003). Likely this is because most coverage of transgender murder victims circulates in local, rather than national, news media (MacKenzie \& Marcel, 2009), and thus the sample of the present study does not adequately represent the full corpus of coverage of transgender murder victims. However, this may also be attributed to the fact that the most heinous forms of delegitimacy are prevalent in crime and murder stories, which thus are of most interest to scholars. Nearly $40 \%$ of all paragraphs in crime/murder stories that name a transgender person use their birth name, which is over one and a half times the amount of misnaming in the second most misnaming story type, tabloid. This could, in part, be attributable to journalists' reliance on official police sources for information about crimes (Sacco, 1995), and the police's reliance in turn on official government identification. However, crime/murder stories also contained the most improper past tense references, suggesting that perhaps the issue is greater than official sourcing patterns. Additionally, crime and murder stories are more frequently about transgender women than transgender men or non-binary transgender people (Schilt \& Westbrook 2009), and in the present study, all of the crime and murder stories in the sample were about transgender women.

Throughout the timeframe of the study, transgender women were the focus of news coverage, while non-binary transgender people were almost completely ignored, supporting the similar conclusions of past studies (Capuzza, 2014; Siebler, 2010; Skidmore, 2011; Squires \& Brouwer, 2002; Willox, 2003). As Siebler (2010) argued, American media insist on assigning transgender people the category of male-to-female or female-to-male, because it is presumed in American culture that "there is [no] way to exist ... as a trans person without surgery and hormones" (p. 323). Therefore, non-binary transgender people must be ignored, or, as Gerbner and Gross (1976) would put it, symbolically annihilated. Similarly, the near invisibility of transgender men compared to transgender women signals a hierarchy of significance in American culture, which finds transgender women more shocking or intriguing; American media (both mainstream and queer) have a long history of focusing discussions of transgenderism on discussions of transgender women (Raz Link \& Raz, 2007). Perhaps this is because, as Schilt and Westbrook (2009) argued, the policing of gender and sexual identity is itself gendered; transgender women are more often punished by our masculinity-centered culture for transgressing gender expectations than transgender men are for transgressing the expectations of femininity. The larger amount of coverage is not to transgender women's benefit, however. In the sample, transgender women are mischaracterized more often, and are more frequently the targets of the most heinous forms of delegitimizing language: slurs and name-calling, defamation, and sexualization. Considering also the work of many second-wave feminist thinkers (e.g., Steinem, 1995), who have argued that the policing of women's bodies precludes gender equality, these findings have negative implications for the present and future acceptance of transgender women.

Although these most severe forms of delegitimizing language are the least frequent, they combine with the other forms of delegitimizing language to potentially impact public perceptions of transgen- 
derism, particularly regarding legitimacy. As Shrum (2002) has written, "people make judgments about other persons, they tend to use the constructs that are most readily accessible from memory" (p. 74). The vividness of these delegitimizing representations, in that they provoke strong emotion and evocative imagery, will be much more easily accessible (Higgins \& King, 1981). There is a particularly rich literature on the importance of accessibility to perceptions of issues discussed in news media, which has found that vivid representations have a much higher impact on audience perceptions than "more accurate but pallid base-rate information" (Shrum, 2002, p. 75; see Gibson \& Zillmann, 1994; Zillmann, Gibson, Sundar, \& Perkins, 1996). Moreover, these representations have the potential to impact not only public perceptions of transgenderism, but also to impact transgender self-perceptions. Although there is room for much more research on the topic, Ringo (2002) has shown that media influence transgender individuals' self-identification processes, which often results in negative self-perceptions pertaining to identity.

Finally, this study represents one of few applications of Hallin's (1986) model of spheres of legitimacy to contexts outside of protest movements and anti-war activism. It further operationalized "legitimacy" in the context of transgender coverage, identifying the "distinguishing features by which legitimacy and deviance are conferred" (Taylor, 2014, p. 41) in a manner previous studies have not. Analysis of the data in this study also illustrated the movement of groups and issues through these spheres over time, which previous studies have only alluded to but not demonstrated (Taylor, 2014).

It must be noted, however, that this study has several key limitations. First, the data presented in this study represent a snapshot of a relatively brief period of time. Particularly because of the very recent increases and evolutions in transgender visibility in media (e.g., Caitlyn Jenner, Laverne Cox, Janet Mock, Jazz Jennings, Carmen Carrera, Transparent), these data tell an incomplete story. For example, on May 4, 2015 the New York Times launched "Transgender Today," a series of editorials on the experiences and challenges of the transgender community, greatly increasing coverage in its own pages, and likely in the pages of many other newspapers around the country for, as prior research as shown, coverage of topics in the New York Times causes increases in coverage of those topics in other news sources (Mazur, 1987; Ploughman, 1984; Reese \& Danielian, 1989). That said, the New York Times' increase in coverage has not entirely meant an increase in legitimizing coverage (see Maza, 2015), so the future of transgender news media representations remains unclear.

Additionally, Legitimacy Indicators 5 through 9 were found infrequently enough in the sample that the analyses here presented cannot be assumed to be true independent of error. Likewise, because the sample was relatively small the results of many of the trend analyses were nonsignificant, though the apparent trends may in reality be occurring.

Finally, the current study only analyzed content from legacy print newspapers. While legacy print newspapers are of particular significance in the political realm, online news media and social media are increasingly important as well (Tewksbury \& Rittenberg, 2012). Moreover, local newspaper coverage is incredibly important to the formation of social and political attitudes (Nielsen, 2015), as are television news sources (Dixon \& Williams, 2015).

As such, future studies should investigate the content of news media not discussed here, such as online news media, local newspapers, television news sources, and social media. Future studies should also expand on the present one by investigating the visual framing of transgender news coverage in both photographs and videos accompanying text articles, building on the work of Cram (2012) and Landau (2012). Additionally, future studies should empirically investigate the effects that transgender news coverage has on the development of readers'/viewers' attitudes toward transgender issues and individuals, particularly as transgender issues are entering mainstream political debate. 


\section{References}

Adams, M. A. (2015). Traversing the transcape: A brief historical etymology of trans* terminology. In L. G. Spencer \& J. C. Capuzza (Eds.), Transgender communication studies: Histories, trends, and trajectories (pp. 173185). Lanham, MD: Lexington Books.

Alliance for Audited Media. (2012, September). Top 25 U.S. newspapers for September 2012. Arlington Heights, IL: Alliance for Audited Media. Retrieved from http://auditedmedia.com/news/researchand-data/top-25-us-newspapers-for-september-2012/

Arune, W. (2006). Transgender images in the media. In L. Castenada \& S. Campbell (Eds.), News and sexuality: Media portraits of diversity (pp. 111133). Thousand Oaks, CA: Sage.

Baker, P. (2010). Representations of Islam in British broadsheet and tabloid newspapers 19992005. Journal of Language and Politics, 9(2), 310338.

Barker-Plummer, B. (2013). Fixing Gwen: News and the mediation of (trans)gender challenges. Feminist Media Studies, 13(4), 710724.

Calzo, J. P., \& Ward, L. M. (2009). Media exposure and viewers attitudes toward homosexuality: Evidence for mainstreaming or resonance? Journal of Broadcasting $\&$ Electronic Media, 53(2), 280299.

Capuzza, J. (2014). Who defines gender diversity? Sourcing routines and representation in mainstream U.S. news stories about transgenderism. International Journal of Transgenderism, 15(3), 115128.

Capuzza, J. C. (2015). Whats in a name? Transgender identity, metareporting, and the misgendering of Chelsea Manning. In L. G. Spencer \& J. C. Capuzza (Eds.), Transgender communication studies: Histories, trends, and trajectories (pp. 93110). Lanham, MD: Lexington Books.

Chavez, K. R. \& Griffin, C. L. (2012). Introduction: Standing at the intersections of feminisms, intersectionality, and communication studies. In K. R. Chavez \& C. L. Griffin (Eds.), Standing in the intersection: Feminist voices, feminist practices in communication studies (pp. 131). Albany: SUNY Press.

Cloud, D. L. (2014). Private Manning and the chamber of secrets. QED, 1(1), p 80104.

Cram, E. D. (2012). Angie was our sister: Witnessing the trans-formation of disgust in the citizenry of photography. Quarterly Journal of Speech, 98(4), 411438.

Dixon, T. L., \& Williams, C. L. (2015). The changing misrepresentations of race and crime on network and cable news. Journal of Communication, 65(1), 2439.

Gamson, J. (1998a). Publicity traps: Television talk shows and lesbian, gay, bisexual, and transgender visibility. Sexualities, $1(1), 1141$.

Gamson, J. (1998b). Freaks talk back: Tabloid talk shows and sexual nonconformity. Chicago: University of Chicago Press.

Gamson, W. A., Croteau, D., Hoynes, W., \& Sasson, T. (1992). Media images and the social construction of reality. Annual Review of Sociology, 18, 373393.

Gerbner, G., \& Gross, L. (1976). Living with television. Journal of Communication, 26 (2), 172199.

Gibson, R., \& Zillmann, D. (1994). Exaggerated versus representative exemplification in news reports. Communication Research, 21, 603624.

Gitlin, T. (1980). The whole world is watching: Mass media in the making and unmaking of the New Left. Berkeley: University of California Press.

GLAAD. (2014, August). Media reference guide (9th ed.). Los Angeles: GLAAD. Retrieved from http://www.glaad.org/sites/default/files/GLAAD

Gross, L. (1991). Out of the mainstream: Sexual minorities and the mass media. Journal of Homosexuality, 21(1-2), 1946.

Gross, L. (2001). Up from invisibility: Lesbians, gay men, and the media in America. New York: Columbia University Press. 
Hale, C. J. (1998). Consuming the living, dis(re)membering the dead in the butch/FTM borderlands. $G L Q, 4(2), 311348$.

Hallin, D. C. (1986). The uncensored war: The media and Vietnam. Berkeley: University of California Press.

Higgins, E. T., \& King, G. (1981). Accessibility of social constructs: Information procession consequences of individual and contextual variability. In N. Cantor \& J. F. Kihlstrom (Eds.), Personality, cognition and social interaction (pp. 69121). Hillsdale, NJ: Lawrence Erlbaum Associates.

Kendall, M. G. (1975). Rank correlation methods (4th ed.). London: Charles Griffin.

Krippendorff, K. (2004). Content analysis: An introduction to its methodology. Newbury Park, CA: Sage.

Landau, J. (2012). Reproducing and transgressing masculinity: A rhetorical analysis of women interacting with digital photographs of Thomas Beatie. Womens Studies in Communication, $35(2), 178203$.

Luther, C. A., \& Miller, M. M. (2005). Framing of the 2003 U.S.-Iraq War demonstrations: An analysis of news and partisan texts. Journalism \& Mass Communication Quarterly, 82(1), 7896.

MacKenzie, G., \& Marcel, M. (2009). Media coverage of the murder of U.S. transwomen of color. In L. M. Cuklanz \& S. Moorti (Eds.), Local violence, global media: Feminist analyses of gendered representations (pp. 79106). New York: Peter Lang.

Mann, H. B. (1945). Non-parametric tests against trend. Econometrica, 13, 163171.

Maza, C. (2015, August 26). The New York Times stumbling, problematic transgender coverage [Web log post]. Retrieved from http://mediamatters.org/blog/2015/08/26/the-new-york-timesstumbling-problematic-transg/205156

Mazur, A. (1987). Putting radon on the public risk agenda. Science, Technology and Human Values, 12, 8693

McLeod, D. M., \& Hertog, J. K. (1992). The manufacture of public opinion by reporters: Informal cues for public perceptions of protest groups. Discourse and Society, 3(3), 259275.

Meyerowitz, J. (1998). Sex change and the popular press: Historical notes on transsexuality in the United States, 1930-1955. GLQ, 4(2), 159188.

Murray, C., Parry, K., Robinson, P., \& Goddard, P. (2008). Reporting dissent in wartime: British press, the anti-war movement and the 2003 Iraq War. European Journal of Communication, $23(1), 727$.

National Lesbian \& Gay Journalists Association. (n.d.). Transgender reporting. Retrieved from http://www.nlgja.org/stylebook/transgender-reporting/

Nielsen, R. K., (Ed.). (2015). Local journalism: The decline of newspapers and the rise of digital media. London: I.B. Tauris.

Pelizzon, V. P., \& West, N. M. (2010). Tabloid, Inc.: Crimes, newspapers, narratives. Columbus: Ohio State University Press.

Pieper, L. P. (2013). Mike Penner or Christine Daniels: The U.S. media and the fractured representation of a transgender sportswriter. Sport in Society, 18(2), 186201.

Ploughman, P. (1984). The creation of newsworthy events: An analysis of newspaper coverage of the man-made disaster at Love Canal (Unpublished doctoral dissertation). State University of New York, Buffalo, NY.

Raz Link, A., \& Raz, H. (2007). What becomes you. Lincoln, NE: University of Nebraska Press.

Reese, S. D., \& Danielian, L. (1989). Intermedia influence and the drug issue: Converging on cocaine. In P. Shoemaker (Ed.), Communication campaigns about drugs (pp. 2946). Hillsdale, NJ: Lawrence Erlbaum Associates. 
Riggle, E. D., Ellis, A. L., \& Crawford, A. M. (1996). The impact of media contact on attitudes towards gay men. Journal of Homosexuality, 31(3), 5569.

Ringo, P. (2002). Media roles in female-to-male transsexual and transgender identity formation. International Journal of Transgenderism, 6(3).

Roen, K., Blakar, R. \& Nafstad, H. (2011). Disappearing transsexuals? Norwegian trans-discourses, visibility, and diversity. Psykologisk Tidsskrift, 1, 2833.

Ryan, J. R. (2009). Reel images: Examining the politic of trans images in film and media (Doctoral dissertation).

Sacco, V. F. (1995). Media constructions of crime. Annals of the American Academy of Political and Social Science, 539, 141154.

Schiappa, E., Gregg, P., \& Hewes, D. (2006). Can one TV show make a difference? Will \& Grace and the parasocial contact hypothesis. Journal of Homosexuality, 51, 1537.

Schilt, K. \& Westbrook, L. (2009). Doing gender, doing heteronormativity: Gender normal, transgender people, and the social maintenance of heterosexuality. Gender \& Society, 23(4), 440464.

Shrum, L. J. (2002). Media consumption and perceptions of social reality: Effects and underlying processes. In J. Bryant, \& D. Zillmann (Eds.), Media effects: Advances in theory and research (pp. 6995). Mahwah, NJ: Lawrence Erlbaum Associates.

Siebler, K. (2010). Transqueer representation and how we educate. Journal of LGBT Youth, 7, 320345 .

Skidmore, E. (2011). Constructing the good transsexual: Christine Jorgensen, whiteness, and heteronormativity in the mid-Twentieth-century press. Feminist Studies, 2(37), 270300.

Sloop, J. (2000). Disciplining the transgendered: Brandon Teena, public representation, and normativity. Western Journal of Communication, 64 (2), 165189.

Sloop, J. (2004). Disciplining gender: Rhetorics of sex identity in contemporary U.S. culture. Amherst: University of Massachusetts Press.

Spencer, L. G. (2015). Introduction: Centering transgender studies in communication scholarship. In L. G. Spencer \& J. C. Capuzza (Eds.), Transgender communication studies: Histories, trends, and trajectories (pp. ixxxii). Lanham, MD: Lexington Books.

Squires, C., \& Brouwer, D. (2002). In/discernible bodies: The politics of passing in dominant and marginal media. Critical Studies in Media Communication, 19(3), 283310.

Steinem, G. (1995). Outrageous acts and everyday rebellions (2nd ed.). New York: Henry Holt and Company.

Taylor, I. (2014). Local press reporting of opposition to the 2003 Iraq War in the UK and the case for reconceptualizing notions of legitimacy and deviance. Journal of War $\mathscr{6}$ Culture Studies, $7(1), 3653$.

Tewksbury, D., \& Rittenberg, J. (2012). News on the Internet: Information and citizenship in the 21st century. Oxford: Oxford University Press.

Willox, A. (2003). Branding Teena: (Mis)representations in the media. Sexualities, 6(3), 407425.

Yep, G. A., Russo, S. E., \& Allen, J. (2015). Pushing boundaries: Toward the development of a model for transing communication in (inter)cultural contexts. In L. G. Spencer \& J. C. Capuzza (Eds.), Transgender communication studies: Histories, trends, and trajectories (pp. 6989). Lanham, MD: Lexington Books.

Zillmann, D., Gibson, R., Sundar, S. S., \& Perkins, J. W. (1996). Effects of exemplification in news reports on the perception of social issues. Journalism $\mathcal{E}$ Mass Communication Quarterly, 73, 427444 . 


\section{Appendix}

\section{Intercoder Reliability Scores}

\begin{tabular}{lcc} 
Code & \% Agreement & Krippendorff's $\alpha$ \\
\hline Legitimacy Indicator (LI) 1: Naming & 98.4 & 0.942 \\
LI 2: Pronoun Usage & 99.1 & 0.982 \\
LI 3: Past Tense References & 99.3 & 0.906 \\
LI 4: Application of Terms & 98.8 & 0.953 \\
LI 5: Characterizations of Transgenderism & 98.8 & 0.900 \\
LI 6: Slurs and Name-Calling & 99.3 & 0.947 \\
LI 7: Defamation & 99.8 & 0.956 \\
LI 8: Shock Tactics & 98.2 & 0.912 \\
LI 9: Genital Focus/Sexualization & 99.8 & 0.983 \\
\hline
\end{tabular}

